\title{
Palm Oil-Derived Phytosterol: Glutathione Antioxidant Status in Rats Exposed to Carbon Tetrachloride
}

\author{
Mohd Fahami Nur Azlina*, Haji Mohd Saad Qodriyah, Mohamed Norazlina, Yusof Kamisah, Ahmad Shuid Nazrun, \\ Marzuki Alini ${ }^{\dagger}$ \\ Department of Pharmacology, Faculty of Medicine, Universiti Kebangsaan Malaysia, JalanYaacob Latif, 56000 Cheras, Kuala Lumpur, Malaysia. \\ ${ }^{\ddagger}$ Faculty of Pharmacy, Cyberjaya Univerisity College of Medical Sciences, 63000 Cyberjaya, Malaysia.
}

\begin{tabular}{l} 
ARTICLE INFO \\
\hline Article history: \\
Received on: $15 / 05 / 2016$ \\
Revised on: 06/06/2016 \\
Accepted on: $26 / 06 / 2016$ \\
Available online: $30 / 08 / 2016$ \\
\hline Key words: \\
phytosterol; carbon \\
tetrachloride; glutathione; \\
antioxidant status.
\end{tabular}

\begin{abstract}
The aim of this study was to assess the antioxidant effect of phytosterol from palm oil by studying its ability to improve antioxidant status of rats induced with oxidative stress by carbon tetrachloride $\left(\mathrm{CCl}_{4}\right)$. The rats were divided into four groups of normal control $(\mathrm{NC})$, carbon tetrachloride $\left(\mathrm{CCl}_{4}\right)$, phytosterol $(\mathrm{P})$ and phytosterol plus carbon tetrachloride $\left(\mathrm{P}+\mathrm{CCl}_{4}\right)$. The $\mathrm{P}$ and $\mathrm{P}+\mathrm{CCl}_{4}$ groups received weekly phytosterol pre-treatment via subcutaneous injections at $140 \mathrm{mg} / \mathrm{kg}$ rat weight for 5 weeks while the $\mathrm{NC}$ and $\mathrm{CCl}_{4}$ groups only received olive oil (vehicle). Carbon tetrachloride at the dose determined by a preliminary study was given as single oral dose to induce lipid peroxidation in the $\mathrm{CCl}_{4}$ and $\mathrm{P}+\mathrm{CCl}_{4}$ groups. After 24 hours, the rats were sacrificed and the heart, liver, kidney and lung were isolated for the determination of reduced glutathione (GSH) and oxidized glutathione (GSSG) levels. Carbon tetrachloride caused significant reduction in the GSH:GSSH ratio in all major organs. Phytosterol pre-treatment as in the $\mathrm{P}+\mathrm{CCl}_{4}$ group significantly increased the GSH:GSSG ratio in major organs. The present findings indicate that phytosterols keep tissue glutathione concentration in normal levels which may indicate improving antioxidant status in major organs of the rats treated with carbon tetrachloride.
\end{abstract}

\section{INTRODUCTION}

Links between oxidative stress and adverse health effects have been suggested for several groups of diseases, including cardiovascular, respiratory, gastrointestinal and neurological (Marx 1987; Nur Azlina et al., 2009, Nur Azlina et al., 2013; Lee et al., 2013). It is well known that these changes are mediated by free radical damage to lipids, proteins, and DNA. Protection from damage occurs through the action of multiple antioxidants either by endogenously produced or provided through dietary intake (Lobo et al., 2010). Uncontrolled production of reactive oxygen species contributes to the

\footnotetext{
* Corresponding Author

Dr Nur Azlina Mohd Fahami, Department of Pharmacology, Faculty of Medicine, Universiti Kebangsaan Malaysia Medical Center, Jalan Yaacob Latif, Cheras, 56000 Kuala Lumpur, Malaysia. Tel No:0603-91459574,E-mail :nurazlinamf@ukm.edu.my
}

pathogenesis of diseases such as cancer and cardiovascular disorders (Vivancos and Moreno, 2005; Azadeh and Mohammad 2011). There were reports which associate lipid peroxidation with coronary or peripheral arterial disease (Lee et al., 2013). Lipid peroxidation is a process in which lipids are oxidized to form radicals and therefore capable of causing extensive tissue. Lipid peroxidation may be the mechanism through which several cardiovascular risk factors may promote cardiovascular disease (Rumly et al., 2004). It is generally believed that oxidative stress may contribute to carcinogenesis by oxidative DNA modification and that antioxidants might prevent human from cancer. A growing body of evidence has demonstrated that lipid peroxidation may actually inhibit most cancer cells (Zanetti et al., 2003; Gago-Dominguez et al., 2005). Therefore, reducing lipid peroxidation is important in prevention of cardiovascular diseases and cancer. Studies have shown this may be achieved through the antioxidant properties of phytosterols. Phytosterols or plant sterols are a group of steroid alcohols, phytochemicals naturally occuring in plants. 
They have chemical structure which are similar to cholesterol (Weihrauch and Gardner 1978, Weingärtner et al., 2009) and exist in several forms in plants (Law, 2000; Katan et al., 2003; Abumweis et al., 2007) including $\beta$-sitosterol, campesterol, stigmasterol and cycloartenol (Ostlund 2002). Phytosterols are natural components found in the human diet. They are found in corn, wheat and rice. Phytosterol intake varies according to the type of diet, European take about 150-400 mg/day (Morton et al.,1995; Susan et al., 2010) while vegetarian Japanese have higher intake (Nair et al., 1984; Seki et al., 2003).

Phytosterols are well known for their ability to lower plasma cholesterol level (Klingberg et al., 2008) by interfering with the absorption of cholesterol from the gastrointestinal system (Jones 1999; Hayes et al., 2004; Jia et al., 2007). Phytosterols have also been shown to possess anticancer properties against certain types of cancer (Choi et al., 2007; Mendilaharsu et al., 1998; De Stefani et al., 2000; McCann et al., 2003; Ju et al. 2004). These studies imply that phytosterols maybe useful in prevention of both cardiovascular disease and cancer.

Phytosterols were found to exert antioxidant effects on the oxidation of methyl linoleate in solution. They also suppressed the oxidation and consumption of $\alpha$-tocopherol in $\beta$-linoleoyl- $\gamma$ palmitoyl phosphatidylcholine (PLPC) liposomal membranes (Yoshida and Niki, 2003). This study showed that phytosterols can act as antioxidants and free-radical scavengers. In another study by Vivancos and Moreno (2005), it was reported that phytosterol increased the activities of antioxidant enzymes, superoxide dismutase and glutathione peroxidase in cultured macrophage cells with oxidative stress induced by phorbol 12-myristate 13-acetate. This finding provided another mechanism whereby phytosterols were able to protect cells from oxidative stress damage by increasing the activities of antioxidant enzymes.

There are limited published reports on the effects of phytosterol from palm oil on endogenous antioxidant levels. Therefore we have conducted a study on the effects of pre-treatment with phytosterol on the level of reduced and oxidized glutathione levels in plasma and organs of rats exposed to carbon tetrachloride. This is important to justify the role of phytosterols in their ability to control oxidative stress and prevention of its related diseases.

\section{MATERIAL AND METHODS}

A preliminary study was conducted to determine the suitable dose of carbon tetrachloride which can induce lipid peroxidation in various organs of the rat model. Carbon tetrachloride is an old animal model; it was discovered that the dose of carbon tetrachloride that produced significant lipid peroxidation in the liver was $0.5 \mathrm{ml} / \mathrm{kg}$ (Hismiogullari et al., 2014).

After the dose selection, 24 male Sprague-Dawley rats weighing between 175 to 200 grams were obtained from the UKM Animal House. The rats were housed in plastic cages at room temperature $\left(29 \pm 3^{\circ} \mathrm{C}\right)$ and daily dark/light cycle. They were fed standard food pellets (Gold Coin, Malaysia) and distilled water ad libitum. They were allowed to adjust to the new environment for a week before the study was started. The study was approved by the Universiti Kebangsaan Malaysia, Animal Ethic Committee.

The rats were randomly divided into 4 groups of normal control (NC), Carbon tetrachloride $\left(\mathrm{CCl}_{4}\right)$, Phytosterol (P) and Phytosterol + Carbon tetrachloride $\left(\mathrm{P}+\mathrm{CCl}_{4}\right)$. The latter two groups were pre-treated with subcutaneous injection of phytosterol (MPOB, Malaysia) at the dose of $140 \mathrm{mg} / \mathrm{kg}$, once a week for five weeks (modified from Yoshida and Niki 2003). These phytosterols were extracted from palm oil and composed of $60 \% \beta$-sitosterol and $40 \%$ stigmasterol and campesterol. The $\mathrm{NC}$ and $\mathrm{CCl}_{4}$ groups only received $2 \mathrm{ml} / \mathrm{kg}$ olive oil (vehicle) (Oomerbhoy Ltd, Mumbai) subcutaneously once a week for the same duration. Rats in the $\mathrm{CCl}_{4}$ and $\mathrm{P}+\mathrm{CCl}_{4}$ groups were then given a single dose of $0.5 \mathrm{ml} / \mathrm{kg}$ carbon tetrachloride (BDH Chemicals, England) diluted in olive oil via oral gavage to induce lipid peroxidation. Rats in the $\mathrm{NC}$ and $\mathrm{P}$ groups only received equivalent amounts of olive oil (vehicle). After 24 hours, the rats were then sacrificed humanely and the liver, heart, kidneys and lungs were dissected out. The organs total glutathione and oxidized glutathione levels were measured according to the method of Griffith (1979). Reduced glutathione (GSH) is considered to be one of the most important scavengers of reactive oxygen species (ROS), and its ratio with oxidised glutathione (GSSG) may be used as a marker of oxidative stress (Zitka et al., 2012).

The results are expressed as mean \pm SEM. The statistical significance of the data was determined using one-way analysis of variance (ANOVA) and post hoc Tukey test. The level of significance was taken as $\mathrm{p}<0.05$.

\section{RESULTS}

Reduced glutathione (GSH) is the major endogenous antioxidant in life organism. The results are expressed by the ratio of GSH to the oxidized form of glutathione (GSSG). Exposure to $\mathrm{CCl}_{4}$ resulted in a significant reduction of hepatic glutathione level by $38.8 \%(\mathrm{P}=0.027)$ compared to the control (NC) group as shown in Figure 1.

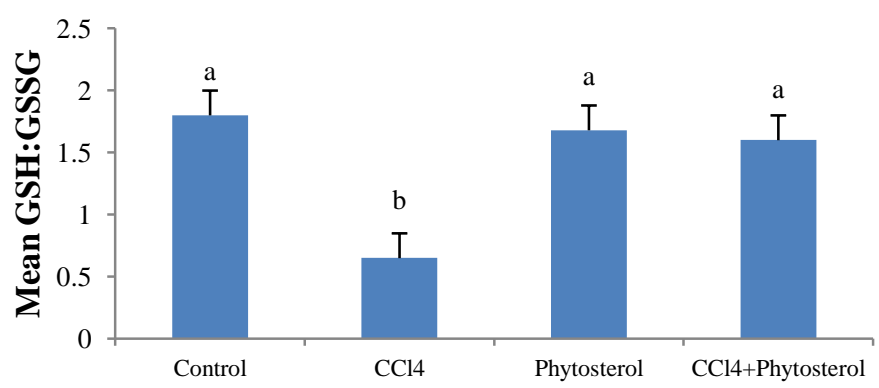

Fig. 1: Mean GSH: GSSG in liver. Different letters indicate significant differences between group at $\mathrm{p}<0.05$. Data is expressed as mean $\pm \mathrm{SEM}$.

Rats treated with phytosterols showed no significant different in the hepatic glutathione level compared to the nonexposed control. The finding suggests that phytosterols can restore 
a normal hepatic glutathione level which was altered by $\mathrm{CCl}_{4}$.

Similar result was observed in renal tissue. Phytosterols pre-treatment caused renal GSH:GSSH ratio elevation in rats induced with carbon tetrachloride compared to the $\mathrm{CCL}_{4}$ group (Figure 2).



Fig. 2: Mean GSH: GSSG in the kidneys. Different letters indicate significant differences between group at $\mathrm{p}<0.05$. Data is expressed as mean $\pm \mathrm{SEM}$.

In the heart, there was also a significant reduction in GSH:GSSG ratio for the $\mathrm{CCl}_{4}$ group compared to the normal control group (Figure 3).

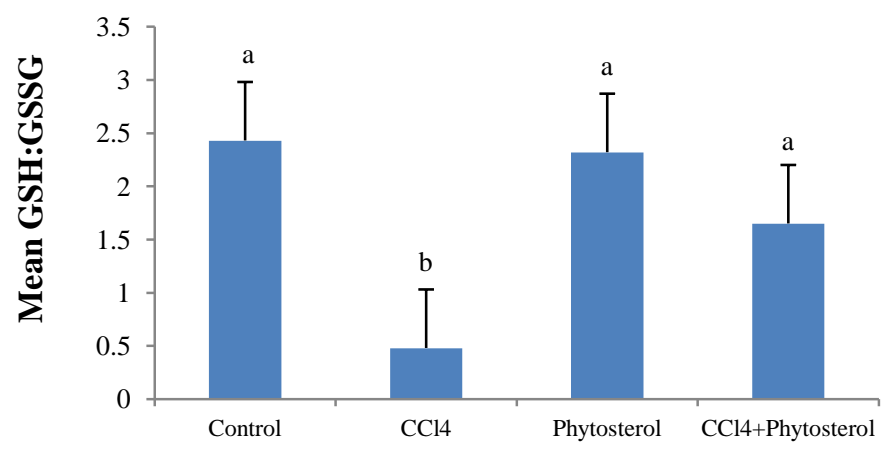

Fig. 3: Mean GSH: GSSG in the heart. Different letters indicate significant differences between group at $\mathrm{p}<0.05$. Data is expressed as mean \pm SEM.

Phytosterols pre-treatment maintained the cardiac GSH:GSSG ratio induced by carbon tetrachloride towards the normal value. In the lungs, a similar observation was shown, where there was a significant reduction of the GSH: GSSG ratio in the $\mathrm{CCl}_{4}$ group (Figure 4).

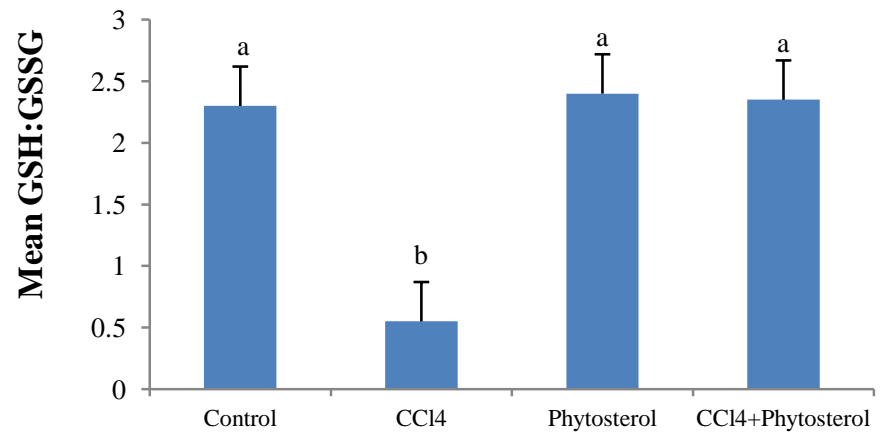

Fig. 4: Mean GSH: GSSG in the lung. Different letters indicate significant differences between group at $\mathrm{p}<0.05$. Data is expressed as mean $\pm \mathrm{SEM}$.
These ratios however, were maintained to the normal control value after $\mathrm{CCl}_{4}$ exposure in rats pre-treated with phytosterols. The mean values for the reduced and oxidized glutathione for all groups are shown in Table 1.

Table 1: Mean of GSH and GSSG in the rat's organs.

\begin{tabular}{|c|c|c|c|c|c|}
\hline & 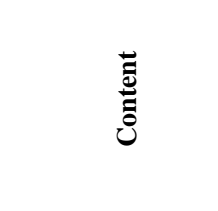 & 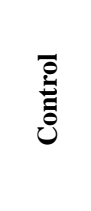 & 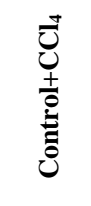 & 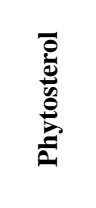 & 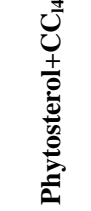 \\
\hline \multirow{2}{*}{ Liver } & GSH (nmol/mg) & 0.6434 & 1.1433 & 0.7390 & 0.8290 \\
\hline & GSSG (nmol/mg) & 1.2451 & 0.6316 & 1.2794 & 1.4192 \\
\hline \multirow{2}{*}{ Lung } & GSH (nmol/mg) & 0.4000 & 0.1182 & 0.3438 & 0.3606 \\
\hline & GSSG (nmol/mg) & 0.1828 & 0.2240 & 0.1456 & 0.1599 \\
\hline \multirow{2}{*}{ Heart } & GSH (nmol/mg) & 0.4409 & 0.1164 & 0.4308 & 0.4445 \\
\hline & GSSG (nmol/mg) & 0.2032 & 0.2751 & 0.2116 & 0.2490 \\
\hline \multirow{2}{*}{ Kidney } & GSH (nmol/mg) & 0.0873 & 0.0150 & 0.0721 & 0.0741 \\
\hline & GSSG (nmol/mg) & 0.0187 & 0.0560 & 0.0267 & 0.0248 \\
\hline
\end{tabular}

\section{DISCUSSION}

Humans are continuously exposed to different chemicals from food, air and soil (Hasegawa 1995). Some of these chemicals induced free-radical-mediated lipid peroxidation leading to disruption of biomembranes and dysfunction of cells and tissues (Ayala et al., 2014, Cho et al., 2003). Carbon tetrachloride is an extensively used xenobiotic to induce lipid peroxidation and toxicity (Rudnicki et al., 2007). In our study, carbon tetrachloride has reduced the endogenous antioxidant levels as shown by the reduction in the GSH:GSSG ratio in all organ indicating an increased in oxidative stress levels in the rats. The failure of the endogenous antioxidant defence system was attributed to the carbon tetrachloride-induced generation of free radicals. We observed a significant depletion of glutathione content in all major organs following exposure to this stressor.

Reduced glutathione (GSH) acts as a non-enzymatic antioxidant that reduces $\mathrm{H}_{2} \mathrm{O}_{2}$, hydroperoxides ( $\mathrm{ROOH}$ ) and xenobiotic toxicity (Kadiska et al., 2000). Reduced glutathione is readily oxidized to glutathione disulfide (GSSG) by any of the selenium-containing GPx isozymes, as well as the reaction with $\mathrm{ROOH}$ or xenobiotic compounds that may subsequently cause the reduction of GSH level. The GSSG is either rapidly reduced by glutathione reductase and $\mathrm{NADPH}$ or utilized in the protein folding process in the endoplasmic reticulum. There, GSSG is recycled by protein disulfide isomerase to form GSH. Because of these recycling mechanisms, GSH is an extremely efficient intracellular buffer for oxidative stress (Cantinet al., 2007). Mechanistic studies on $\mathrm{CCl}_{4}$-induced toxicity reveal that $\mathrm{GSH}$ conjugation plays a critical role in the elimination of toxic metabolites, which are the major cause of liver pathology (Lee et al., 2008). In the present study, the liver, heart, kidneys and lungs content of GSH was significantly decreased in carbon tetrachloride-intoxicated rats compared with control rats, suggesting a role of GSH in $\mathrm{CCl}$-induced toxicities. The 
mechanism of multiple organ protection by palm-derived phytosterols against $\mathrm{CCl}_{4}$ toxicity might be due to restoration of the GSH level. Pre-treatment with phytosterol extract increased the levels of GSH which may possibly be due to enhancing of GSH synthesizing enzyme activities such as c-glutamylcysteine synthetase (c-GCS) and GSH synthetase, suggesting that these phytosterols could preserve the carbon tetrachloride-induced depletion of GSH in major organ. These however need further investigation. Similarly, Oyedemi and Afolayan (2011) had showed that aqueous leaves extract of Leonotis leonurus extract effectively increased the percentage inhibition of GSH. While Kamisah et al., (2011) had shown palm-derived vitamin E had the ability to reduce oxidative stress in rat's stomach.

Carbon tetrachlorides is known to cause injuries to the organs of the body (Reynolds et al.,, 1984) including liver (Nevin et al., 2005; Shim et al., 2010), kidneys (Ozturk et al., 2003), heart, lungs, gastrointestinal tract and central nervous system (ATSDR 2005). The primary targets for carbon tetrachloride toxicity are liver and kidneys (IPCS 1999). In the body, carbon tetrachloride is metabolised by cytochrome P-450 enzymes to reactive trichloromethyl radical. The radical is oxidized further, forming the even more reactive trichlomethyl peroxyl radicals (McGregor and Lang, 1996; IPCS 1999). Lipid peroxidation occurs via reactive metabolic intermediates of carbon tetrachloride, in particular the trichloromethylperoxyl radical (IPCS 1999).

Phytosterols taken into the body are incorporated into the cell membranes (Awad et al., 2004) and are highly concentrated in the lungs, adrenal cortex, intestinal epithelia and ovaries (Sanders et al., 2000). In our study, we found that phytosterol pre-treatment was able to prevent the reduction in the GSH:GSSG ratios in the liver, kidneys, heart and lungs. Based on these findings, pretreatment with phytosterols maintained the endogenous antioxidant system thus showing its ability to reduce lipid peroxidation and protect the organs against damages by lipid peroxidation. This is consistent with the finding that pre-treatment with other antioxidants, such as vitamin E reduced the hepatotoxic action of carbon tetrachloride (IPCS 1999). Other studies had shown, herbs with high antioxidant properties like Nigella sativa oil decreased lipid peroxidation and were capable of preventing the rise of lipoperoxidation due to the nephrotoxic effect of Amikacin (Iman and Mahmoud, 2011). While herbs containing antioxidant was able to protect the liver against carbon tetrachloride effect as demonstrated by the increase in non-protein sulfhydryl level (Syed et al., 2008), reduced malondialdehyde level (Patrick et al., 2010; Bashandy and Alwasel 2011) and liver enzymes (Prakash et al., 2008; Mohammed et al., 2008).

In a study by Mora-Ranjeva et al.,(2006), phytosterol in the form of sitosterol and stigmasterol were incorporated in to human keratinocytes (SVK14 line) and exposed to ultraviolet. It was found that sitosterol induced significant decrease $(-30 \%)$ in lipid peroxidation whereas stigmasterol markedly increased lipid peroxidation $(+70 \%)$. This study had shown that the effects of phytosterol on lipid peroxidation also depended on the form of phytosterol. In our study, we used phytosterols derived from palm oil with $\beta$-sitosterol making up $60 \%$ of the component while campesterol and stigmasterol made up the rest. The high level of stigmasterol in palm-derived phytosterols could explain the reasons for the maintenance of the endogenous glutathione content by its ability to reduce lipid peroxidation (Ajayi and Malachi 2016).

The phytosterols dosage used in this study was equivalent to the intake of 10.5 grams per week in a $75-\mathrm{kg}$ man. This is high considering that the daily intake of phytosterols in the human diet is about 200 to $300 \mathrm{mg} / \mathrm{kg}$ body weight (Susan et al., 2010, Ostlund 2002, Morton et al., 1995). With regard to its toxicity, administration of phytosterols in rats did not show any subchronic toxicity or teratogenic effects (Xiemei et al., 2015). In human study, daily intake of 9.0 grams of phytosterols for eight weeks did not show any adverse effects (Katan et al., 2003).

As a conclusion, the findings indicate therapeutic usefulness of phytosterols in reducing lipid peroxidation as shown by its ability to maintain endogenous antioxidant levels in the liver, kidneys, heart and lungs in $\mathrm{CCl}_{4}$-induced oxidative stress condition. Thus, this agent may be useful as an agent to protect major organs against chemical-induced toxicity in-vivo.

\section{ACKNOWLEDGEMENT}

We would like to thank Universiti Kebangsaan Malaysia for providing the grant for this study (FF-146).

\section{REFERENCES}

Abumweis, SS, Jones PJH. Plant sterols: Natural plant components with potential beneficial health effects. International News on fats, oils and related materials. Inform, 2007; 18:825-828.

Agency for Toxic Substances and Disease Registry (ATSDR). Toxicological Profile for Carbon Tetrachloride, 2005, US Department of Health and Human Services, Atlanta, US.

Ajayi OB, Malachi OI. Comparative Study of Phytosterols and Vitamins A and E Composition of Vegetable Oil Brands Consumed in Nigeria.International Journal of Biochemistry Research and Review. 2016; 1:11(4).

Awad AB, Toczek J, Fink CS. Phytosterols decrease prostaglandin release in cultured P388D1/MAB macrophages. Prostaglandins. Leukot Essent Fatty Acids, 2004; 70:511-520.

Ayala A, Muñoz MF, Sandro Argüelles. Lipid Peroxidation: Production, Metabolism, and Signaling Mechanisms of Malondialdehyde and 4-Hydroxy-2-Nonenal. Oxidative Medicine and Cellular Longevity, 2014; vol. 2014, Article ID 360438: 31 pages.

Azadeh Mohammadirad, Mohammad Abdollahi. A Systematic Review on Oxidant/Antioxidant Imbalance in Aluminium Toxicity. International Journal of Pharmacology, 2011; 7:12-21.

Bashandy SA, AlWasel SH. Carbon Tetrachloride-induced Hepatotoxicity and Nephrotoxicity in Rats: Protective Role of Vitamin C. Journal of Pharmacology and Toxicology, 2011; 6:283-292.

Cantin AM, White TB, Cross CE, Forman HJ, Sokol RJ, Borowitz D. Antioxidants in cystic fibrosis Conclusions from the CF Antioxidant Workshop, Bethesda, MD, November 11-12, 2003. J Free RadicBiol Med, 2007; 42:15-31.

Cho EJ, Yokozawa T, Rhyu DY, Kim HY, Shibahara N., Park JC. The inhibitory effects of 12 medicinal plants and their component compounds on lipid peroxidation. Am J Chin Med, 2003; 31:907. 
Choi J, Lee E, Lee H, Kim K, Ahn K, Shim B. Identification of campesterol from Chrysanthemum coronarium $\mathrm{L}$ and its antiangiogenic activities. Phytother Res, 2007; 21:954-959.

De Stefani E, Boffetta P, Ronco AL, Brennan P, DeneoPellegrini H, Carzoglio JC. Plant sterols and risk of stomach cancer: A case-control study in Uruguay", Nutr Cancer, 2000; 37:140-144.

Gago-Dominguez M, Castelao JE, Pike MC, Sevanian A, Haile RW. Role of lipid peroxidation in the epidemiology and prevention of breast cancer. Cancer EpidemiolBiomar, 2005; 14:2829-2839.

Griffith OW, Meister A. Potent and specific inhibition of glutathione synthesis by buthionine sulfoximine. J Biol Chem, 1979; 254:7558-7560.

Hafsah MY. The effects of phytosterols derived from palm oil on lipid peroxidation exposed to carbon tetrachloride, UKM Honours Thesis, 2005

Halliwell B. Oxidants and human disease: some new concepts. FASEB J, 1987; 1:358-364.

Hasegawa R, Chujo T, Sai-Kato K, Umemura T, Tanimura A, Kurokawa Y. Preventive effects of green tea against liver oxidative DNA damage and hepatotoxicity in rats treated with 2-nitropropane. Food ChemToxicol, 1995; 33:961.

Hayes KC, Pronczuk A, Perlman D. Nonesterified phytosterols dissolved and recrystallized in oil reduces plasma cholesterol in gerbils and humans. J Nutr, 2004; 134:1395-1399.

Hismiogullari AA, Hismiogullari SE, Karaca O, Sunay FB, Paksoy S, Can M, Kus I, Seyrek K, Yavuz O. The protective effect of curcumin administration on carbon tetrachloride (CCl4)-induced nephrotoxicity in rats.Pharmacol Rep, 2015; 67(3):410-6.

Iman Abdelaziz, Mahmoud Kandeel. The Protective Effects of Nigella sativa Oil and Allium sativumExtract on Amikacin-induced Nephrotoxicity. International Journal of Pharmacology, 2011; 7:697-703.

International Programme on Chemical Safety (IPCS) Carbon Tetrachloride. Environmental Health Criteria 208, WHO, Geneva, 1999; $1-177$.

Jia X, Ebine N, Demonty I, Wang Y, Beech R, Muise V. Hypocholesterolemic effects of plant sterol analogues are independent of ABCG5 and ABCG8 transporter expressions in hamsters. Br J Nutr, 2007; 98:550-555.

Jones PJ. Cholesterol-lowering action of plant sterols, Curr Atheroscler Rep, 1999; 1:230-235.

$\mathrm{Ju}$ YH, Clausen LM, Allred KF, Almada AL, Helferich WG. $\beta$

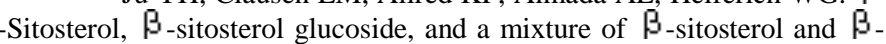
sitosterol glucoside modulate the growth of estrogen-responsive breast cancer cells in vitro and ovariectomized athymic mice. J Nutr, 2004; 134:1145-1151.

Kadiska MB, Gladen BC, Baird DD, Dikalov AE, Sohal RS, Hatch GB, Jones DP, Mason RP, Barret JC. Biomarkers of oxidative stress study: Are plasma antioxidants markers of $\mathrm{CCl} 4$ poisoning? J Free $\mathrm{Rad}$ Biol Med, 2000; 28:838-845.

Kamisah Y, Ibrahim AAI, Nafeeza MI, Nur-Azlina MF. Palm tocotrienol-rich fraction supplementation suppressed stress-induced gastric oxidative stress in rats. J App Pharm Sci, 2011; 1(10):118-122.

Katan MB, Grundy SM, Jones P, Law M, Miettinen T, Paoletti R. Efficacy and safety of plant stanols and sterols in the management of blood cholesterol levels. Mayo ClinProc, 2003; 78:965-978.

Klingberg S, Ellegård L, Johansson I, Hallmans G, Weinehall L, Andersson $\mathrm{H}$. Inverse relation between dietary intake of naturally occurring plant sterols and serum cholesterol in northern Sweden. Am J Clin Nutr, 2008; 87:993-1001.

Lee C-W, Cheng T-M, Lin C-P, Pan J-P. 2013. Plasma haptoglobin concentrations are elevated in patients with coronary artery disease. PLoS ONE 8(10):e76817.

Lee KK, Shimoji M, Hossain QS, Sunakawa H, Aniya Y. Novel function of glutathione transferase in rat liver mitochondrial membrane: Role for cytochrome $\mathrm{C}$ release from mitochondria. Toxicology and Applied Pharmacology, 2008; 232:109-118.

Lobo V, Patil A, Phatak A, Chandra N. Free radicals, antioxidants and functional foods: Impact on human health. Pharmacogn Rev, 2010; 4(8):118-126.
Marx JL. Oxygen free radicals linked to many diseases. Science, 1987; 235:529-531

McCann SE, Freudenheim JL, Marshall JR, Graham S. Risk of human ovarian cancer is related to dietary intake of selected nutrients, phytochemical and food groups. J Nutr, 2003; 133:1937-1942.

McGregor D, Lang M. Carbon tetrachloride: genetic effects and other modes of action. Mutation Research, 1996; 366:181-195.

Mendilaharsu M, Stefani ED, Deneo-Pellegrini H, Carzoglio J, Ronco A. Phytosterols and risk of lung cancer: A case-control study in Uruguay. Lung Cancer, 1998; 21:37-45.

Mohammed NHSH, Abelgasim AI, Mohammed AH. Protective effect of Raphanussativus against carbon tetrachloride induced hepatotoxicity in wistar albino rats. Journal of Pharmacology and Toxicology, 2008; 3:272-278.

Mora-Ranjeva MP, Charveron M, Fabre B, Milon A, Muller I. Incorporation of phytosterols in human keratinocytes. Consequences on UVA-induced lipid peroxidation and calcium ionophore-induced prostaglandin release. Chem Phys Lipids,2006; 141(12):216-224.

Morton GN, Lee SM, Bus DH, Lawrence P. Intakes and major dietary sources of cholesterol and phytosterol in British diet. Journal of Human Nutrition and Dietetics, 1995; 8:429-440.

Nair PP, Trujman N, Kissie G. Diet, nutrition intake and metabolism in population at high and low risk for colom cancer. Dietary cholesterol, $\beta$-sitosterol and stigmasterol. American Journal of Clinical Nutrition, 1984; 40:928-930.

Nevin KG, Vijayammal PL. Effect of Aervalanata against hepatoxicity of carbon tetrachloride in rats. Environmental Toxicology and Pharmacology, 2005; 20:471-477.

Nur Azlina MF, Rubaizah K, SitiMuliana M, Nafeeza MI. Modulation of restraint stress induced gastric oxidative changes in rats by tocotrienol and tocopherol. International Journal of Pharmacology, 2009; 5(1):58-64.

Ostlund RE. Phytosterols in human nutrition. Annu Rev Nutr, $2002 ; 22: 533-549$.

Oxturk F, Ucar M, Azturk C, Vardi N, Batcioglu K. Carbon tetrachloride-induced nephrotoxocity and protective effect of Betaine in Sprague dawley rats. Urology, 2003; 62:353-356.

Oyedemi SO, Afolayan AJ.In vitro and in vivo Antioxidant Activity of Aqueous Leaves Extract of Leonotisleonurus(L.) R. Br. International Journal of Pharmacology, 2011; 7:248-256.

Patrick-Iwuanyanwu KC, Wegwu MO, Okiyi JK. Hepatoprotective Effects of African Locust Bean (Parkiaclappertoniana) and Negro Pepper (Xylopiaaethiopica) in $\mathrm{CCl}_{4}$-Induced Liver Damage in Wistar Albino Rats.International Journal of Pharmacology, 2010; 6:744749.

Prakash O, Singh GN, Singh RM, Mathur SC, Bajpai M, Yadav S. Protective Effect of a Herbal Formula Against Carbontetrachloride Induced Hepatotoxicity. International Journal of Pharmacology, 2008; 4:282-286.

Rafatullah S, Abdulmalik Al-Sheikh, Saleh Alqsoumi, Mohammed Al-Yahya, Kamal El-Tahir and Ahmed Galal. Protective Effect of Fresh Radish Juice (RaphanussativusL.) Against Carbon Tetrachloride-Induced Hepatotoxicity.International Journal of Pharmacology, 2008; 4:130-134.

Reynolds ES, Treinen RJ, Farrish HH, TreinenMoslen M. Metabolism of [14C]carbon tetrachloride to exhaled, excreted and bound metabolites. Biochem Pharmacol, 1984; 33:3363-3374

Rudnicki M, Silveira MM, Pereira TV, Oliveira MR, Reginatto FH, Dal-Pizzol F, Moreira JCF. Protective effects of Passifloraalata extract pretreatment on carbon tetrachloride induced oxidative damage in rats Food Chem. Toxicol, 2007; 45:656-661.

Rumley AG, Woodward M, Rumley A, Rumley J, Lowe GDO. Plasma lipid peroxides: relationships to cardiovascular risk factors and prevalent cardiovascular disease. QJM, 2004; 97(12):809-816.

Sanders DJ, Minter HJ, Howes D, Hepburn PA. The safety evaluation of phytosterol esters Part 6: The comparative absorption and tissue distribution of phytosterols in the rat. Food ChemToxicol, 2000; $38: 485-491$ 
Seki S, Hidaka I, Kojima K, Yoshino H, Aoyama T, Okazaki M, Kondo K. Effects of phytosterol ester-enriched vegetable oil on plasma lipoproteins in healthy men Asia Pacific J ClinNutr, 2003; 12 (3):282-291.

Shim JY, Kim MH, Kim HD, Ahn JY, Yun YS, Song JY. Protective action of the immunomodulator Ginsan against carbon tetrachloride-induced liver injury via control of oxidative stress and inflammatory response. Toxicology and Applied Pharmacology, 2010; 242:318-325.

Susan BR, Xiaobo L, Michael L, Catherine AS, Marlene MM, Lina M, Richard EO Jr. Dose effects of dietary phytosterols on cholesterol metabolism: A controlled feeding study. Am J Clin Nutr, 2010; 91:32-38.

Vivancos M., Moreno JJ. -Sitosterol modulates antioxidant enzyme response in RAW 2647 macrophages. Free Radic Biol Med, 2005; 39:91-97.

Weihrauch JL, Gardner JM. Sterol contents of foods or plant origin. J Am Diet Assoc, 1978; 73:39-47.

Weingärtner O, Böhm M, Laufs U. Controversial Role of Plant Sterol Esters in the Management of Hypercholesterolaemia. Eur Heart J, 2009; 30(4):404-409.

XieXinmei, Xiao Ning, He Jianbin. Physiological Function of Phytosterol and Its Application. Animal Husbandary and Feed Science, 2015; 7(02):9-11.
Yoshida Y, Niki E. Antioxidant effects of phytosterol and its components. J Nutr Sci Vitaminol, 2003; 49(4):277-280.

Zanetti D, Poli G, Vizio B, Zingaro B, Chiarpotto E, Biasi F. 4hydroxynonenal and transforming growth factor-beta1 expression in colon cancer. Mol Aspects Med,2003; 24:273-280.

Zitka O, Skalickova S, Gumulec J. Redox status expressed as GSH:GSSG ratio as a marker for oxidative stress in paediatric tumour patients. Oncology Letters, 2012; 4(6):1247-1253.

\section{How to cite this article:}

Azlina MFN, Qodriyah HMS, Norazlina M, Kamisah Y, Nazrun AS, Alini M. Palm Oil-Derived Phytosterol: Glutathione Antioxidant Status in Rats Exposed to Carbon Tetrachloride. J App Pharm Sci, 2016; 6 (08): 090-095. 